\title{
Standardizing catch and effort data of the Taiwanese distant-water longline fishery in the western and central Pacific Ocean for bigeye tuna, Thunnus obesus
}

\author{
Nan-Jay Su ${ }^{\text {a }}$, Su-Zan Yeh ${ }^{\mathrm{a}}$, Chi-Lu Sun ${ }^{\mathrm{a}, *}$, André E. Punt ${ }^{\mathrm{b}}$, \\ Yong Chen ${ }^{\mathrm{c}}$, Sheng-Ping Wang ${ }^{\mathrm{d}}$ \\ ${ }^{a}$ Institute of Oceanography, National Taiwan University, Taipei 10617, Taiwan \\ ${ }^{\mathrm{b}}$ School of Aquatic and Fishery Sciences, University of Washington, Seattle, WA 98195, United States \\ ${ }^{c}$ The School of Marine Sciences, University of Maine, Orono, ME 04469, United States \\ ${ }^{\mathrm{d}}$ Department of Environmental Biology and Fisheries Science, National Taiwan Ocean University, Keelung 20224, Taiwan
}

Received 13 January 2007; received in revised form 21 October 2007; accepted 23 October 2007

\begin{abstract}
Catch per unit effort (CPUE) is often used as an index of relative abundance in fisheries stock assessments. However, the trends in nominal CPUE can be influenced by many factors in addition to stock abundance, including the choice of fishing location and target species, and environmental conditions. Consequently, catch and effort data are usually 'standardized' to remove the impact of such factors. Standardized CPUE for bigeye tuna, Thunnus obesus, caught by the Taiwanese distant-water longline fishery in the western and central Pacific Ocean (WCPO) for 1964-2004 were derived using three alternative approaches (GLM, GAM and the delta approach), and sensitivity was explored to whether catch-rates of yellowfin tuna and albacore tuna are included in the analyses. Year, latitude, and the catch-rate of yellowfin explained the most of the deviance (32-49\%, depending on model configuration) and were identified consistently among methods, while trends in standardized catch-rate differed spatially. However, the trends in standardized catch-rates by area were found to be relatively insensitive to the approach used for standardization, including whether the catch-rates of yellowfin and albacore were included in the analyses.
\end{abstract}

(C) 2007 Elsevier B.V. All rights reserved.

Keywords: Bigeye tuna; Standardization; CPUE; GLM; GAM; Delta approach

\section{Introduction}

Bigeye tuna (Thunnus obesus Lowe, 1839) is a commercially important species that is widely distributed in tropical and sub-tropical waters of the Atlantic, Indian, and Pacific Oceans. Bigeye can be found between northern Japan and the North Island of New Zealand and from $40^{\circ} \mathrm{N}$ to $30^{\circ} \mathrm{S}$ in the Pacific Ocean (Matsumoto, 1998). Adult bigeye are caught mainly by longline vessels, but a large number of juveniles are also taken by other fishing gears, including purse seines (Sun et al., 2001).

The total longline catch of bigeye in the western and central Pacific Ocean (WCPO) varied between 40,000 and 60,000 mt during the 1980s (Hampton et al., 2006), and increased substan-

\footnotetext{
* Corresponding author. Tel.: +886 23629842; fax: +886223629842. E-mail address: chilu@ntu.edu.tw (C.-L. Sun).
}

tially thereafter to $90,000 \mathrm{mt}$ (Fig. 1). Taiwanese distant-water tuna longline fleets have operated throughout the Atlantic, Pacific and Indian Oceans since the late 1960s. In the WCPO, Taiwanese offshore longline vessels, based at both domestic (primarily Tungkang) and foreign fishing ports, have landed bigeye (Sun et al., 2001).

Despite the fact that the Taiwanese distant-water longline fishery provides data for a substantial fraction of the WCPO and catches by this fishery have increased markedly since the late 1990s (Fig. 1), data from Taiwan have only been used to a limited extent in the assessment and management of bigeye in this region. It is thus appropriate to identify the key factors that may influence catch-rates of bigeye by the Taiwanese distantwater longline fishery, and hence develop a potential index of bigeye abundance using the catch and effort data for this fishery for possible inclusion, along with standardized catch-rate indices based on Japanese longline data, into the stock assessment for this species. 


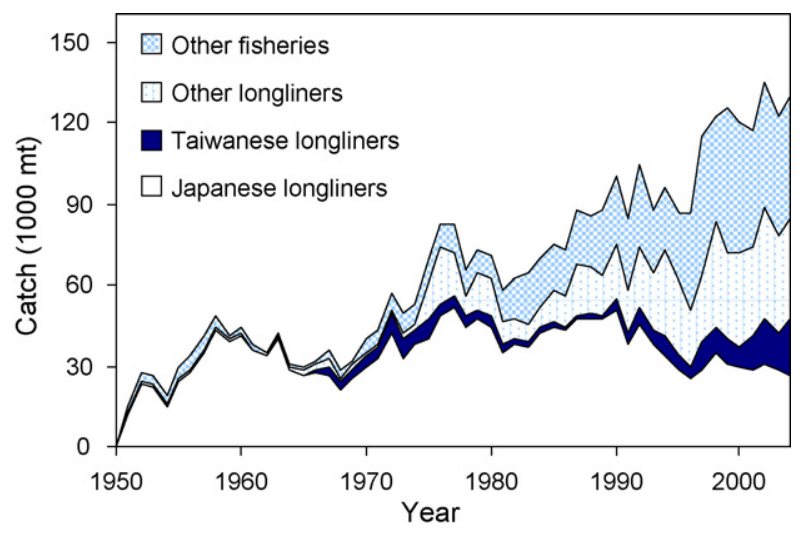

Fig. 1. Annual catches of bigeye (1951-2004) by various fleets in WCPO.

A variety of methods for analyzing catch and effort data have been developed (e.g. see the overview in Maunder and Punt (2004)), including generalized linear models (GLMs), generalized additive models (GAMs), and the delta approach. The objectives of this study are: (1) to use multiple analysis techniques to assess how robustly the factors that might influence the catch-rates of the Taiwanese distant-water longline fishery for bigeye can be identified, and (2) to identify how sensitive standardized catch-rates, in this case for bigeye based on data for the Taiwanese distant-water longline fishery in the WCPO, are to the choice of analytical framework for catch-effort standardization.

\section{Materials and methods}

\subsection{Data}

Catch and effort data, expressed as the number of fish caught and the number of hooks employed, respectively, were obtained for the Taiwanese distant-water longline fishery in the WCPO from the Overseas Fisheries Development Council of the Republic of China. The tuna catch by this fishery consists of three species, bigeye, albacore (Thunnus alalunga), and yellowfin (Thunnus albacares), and this fishery also catches swordfish, billfishes and sharks, although these latter species are not considered in the analyses of this paper. The data were compiled by year, month and $5^{\circ} \times 5^{\circ}$ latitude and longitude grid cell for the period 1964-2004, with catch-rate expressed as the catch in number per 1000 hooks. In addition to catch and effort information, each monthly record also includes temporal (year and month) and spatial information (latitude and longitude), and data on sea surface temperature (SST) and mixed layer depth (MLD). The SST data for 1964-2004 $\left(2^{\circ} \times\right.$ monthly resolution) were obtained from the NOAA/ERSST/V2 dataset provided by the NOAA/OAR/ESRL PSD (http://www.cdc.noaa.gov/) while the MLD data for 1964-2003 ( $2^{\circ}$ latitude by $5^{\circ}$ longitude resolution) were obtained from the Joint Environmental Data Analysis Center (http://jedac.ucsd.edu/) and those for 2004 (10 min resolution) from the dataset http://web.science.oregonstate.edu/ocean.productivity/inputMldData.php. The SST and MLD data were averaged to $5^{\circ}$ grid cells to match the resolution of the fishery data.

\subsection{Covariates and error models}

The covariates considered in the analyses were selected based on their likely impact on bigeye catch-rates, given the results of previous studies (e.g. Sun and Yeh, 2001; RodríguezMarín et al., 2003; Okamoto et al., 2004). These covariates are: year, month, latitude and longitude, SST, MLD, and the catch-rates of albacore and yellowfin. Catch-rates of albacore and yellowfin (denoted YFT_CPUE and $A L B \_C P U E$, respectively) were included in the analyses because these species are also targeted by the Taiwanese distant-water longline fishery (Ortiz, 2005; Langley et al., 2005). Including the catches (or catch-rates) of alternative target species is fairly common when standardizing catch and effort data (e.g. Okamoto et al., 2004; Ortiz, 2005; Andrade et al., 2005) and provides one mechanism for identifying differences over time in species targeting practices (e.g. Stephens and MacCall, 2004). Analyses are conducted separately for each of five fishing areas (Fig. 2) to account for the possibility that the relationship between the covariates and catch-rate is not constant throughout the WCPO. The five-area stratification in Fig. 2 was used by Hampton et al. (2003) to separate the tropics, where both surface and longline fisheries occur year-round, from the higher latitudes, where the longline fisheries occur more seasonally.

Two-way interactions among the main factors (except year) are examined in the GLM analyses, with the interactions selected using backward stepwise methods. Sensitivity is also explored to omitting the catch-rates of yellowfin and albacore owing to the possibility that inclusion of these covariates could lead to biased estimates of trends in standardized catch-rate (Maunder and Punt, 2004).

All of the analyses are based on the assumption that catch-rate is lognormally distributed after log-transformation (and perhaps after the addition of a small constant). Examination of plots of standardized residuals and quantile-quantile plots provide no evidence for violation of this assumption (results not shown).

\subsection{Generalized linear model}

Generalized linear models (GLMs; Nelder and Wedderburn, 1972) are the most commonly used approach for standardizing catch and effort data (Maunder and Punt, 2004). A GLM assumes that the expected value of a transformed response variable is related to a linear combination of exploratory variables (Guisan et al., 2002), i.e.:

$g\left(\mu_{i}\right)=\mathbf{X}_{i}^{T} \beta$

where $g$ is the differentiable and monotonic link function, $\mu_{i}=E\left(Y_{\mathrm{i}}\right), \mathbf{X}_{i}$ is the vector that specifies the explanatory variables for the $i$ th value of the response variable, $\beta$ is a vector of estimable parameters, and $Y_{i}$ the $i$ th response.

The GLM on which the analyses of this paper was based set the response variable to be the natural logarithm of the bigeye catch-rate $+0.1 ; 0.1$ being added to avoid taking the logarithm of zero. All of the explanatory variables were treated as being 


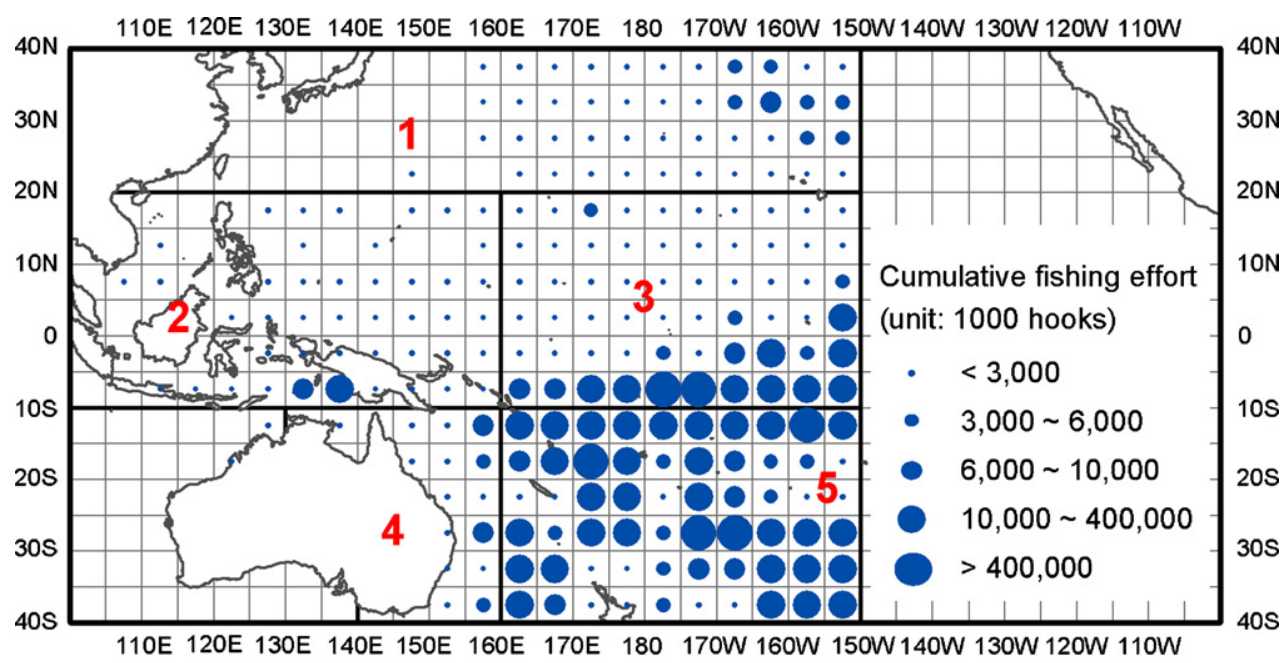

Fig. 2. Distribution of fishing effort (number of hooks) by the Taiwanese distant-water longline fishery (aggregated over 1964-2004 and classified into five levels). The numbers denote the five fishing areas.

categorical when applying the GLM. The continuous variables (catch-rates of yellowfin and albacore, SST and MLD) were transformed into categorical variables by splitting them at their quantiles. The full GLM (including interactions) is:

$$
\begin{aligned}
& \ln \left(\text { CPUE }_{\mathrm{BET}}+0.1\right) \sim \text { Year + Month + SST + MLD } \\
& \quad \text { +YFT_CPUE + ALB_CPUE + Interactions. }
\end{aligned}
$$

\subsection{Generalized additive model}

Generalized additive models (GAMs; Hastie and Tibshirani, 1990) are a semi-parametric extension of GLMs, with the underlying assumption that the response variable is related to smooth additive functions of the explanatory variables (Guisan et al., 2002). The strength of the GAM approach is its ability to deal straightforwardly with non-linear relationships between the dependent variable and multiple explanatory variables rather than being constrained by the parameterization associated with a GLM (Sacau et al., 2005). A GAM can be expressed as:

$g\left(\mu_{i}\right)=\mu+\sum_{j=1}^{p} f_{j}\left(\mathbf{X}_{i}\right)$

where $f_{j}$ is a smooth function, such as a spline or a loess smoother.

In the GAM analyses, year and month were treated as factors while the remaining covariates (including the logarithms of catch-rates of the other tuna species) were treated as continuous variables. One was added to the catch-rates of yellowfin and albacore prior to their inclusion in the GAM analysis. The continuous covariates are included in the GAM analyses as smoother functions with four degrees of freedom (to roughly mimic the degrees of freedom for each main effect in the GLM analyses).

Two approaches are used to handle the fact that the catch of bigeye was zero for some of the $5^{\circ}$ grid cells even though there was some fishing effort for these cells.
(1) The logarithm of the catch-rate of bigeye +0.1 was treated as the response variable, i.e.:

$$
\begin{aligned}
& \ln \left(\text { CPUE }_{\mathrm{BET}}+0.1\right) \sim \text { Year }+ \text { Month } \\
& \quad+\mathrm{s}(\text { Latitude })+\mathrm{s}(\text { Longitude })+\mathrm{s}(\mathrm{SST})+\mathrm{s}(\text { MLD }) \\
& \quad+\mathrm{s}(\text { YFT_CPUE })+\mathrm{s}(\text { ALB_CPUE }) ;
\end{aligned}
$$

where $\mathrm{s}(x)$ denotes a spline smoother (with four degrees of freedom) function of the covariate $x$.

(2) The probability of obtaining a non-zero catch and the catchrate given that the catch is non-zero were modeled using separate GAMs, i.e. following the two-stage procedure outlined by Lo et al. (1992), Stefánsson (1996), and Ortiz and Arocha (2004). The data on presence or absence of bigeye was modeled using logistic regression (the $P / A$ model), while the records for which the catch-rate was positive were modeled assuming a lognormal distribution for the response variable (the CPUE model). The P/A and CPUE models are:

$$
\begin{aligned}
& P / A \sim \text { Year }+ \text { Month }+\mathrm{s}(\text { Latitude })+\mathrm{s}(\text { Longitude }) \\
& +\mathrm{s}(\mathrm{SST})+\mathrm{s}(\mathrm{MLD})+\mathrm{s}(\text { YFT_CPUE }) \\
& +\mathrm{s}(\text { ALB_CPUE })+\text { Effort, and }
\end{aligned}
$$

$$
\begin{aligned}
& \ln \left(\text { CPUE }_{\mathrm{BET}}\right) \sim \text { Year }+ \text { Month }+\mathrm{s}(\text { Latitude }) \\
& \quad+\mathrm{s}(\text { Longitude })+\mathrm{s}(\mathrm{SST})+\mathrm{s}(\mathrm{MLD})+\mathrm{s}(\text { YFT_CPUE }) \\
& \quad+\mathrm{s}(\text { ALB_CPUE }) ;
\end{aligned}
$$

where $P / A$ is one if at least one bigeye was caught and zero otherwise.

The P/A model includes effort as a covariate because the probability of obtaining a zero catch in a particular grid cell is expected to depend on the amount of effort expended. 


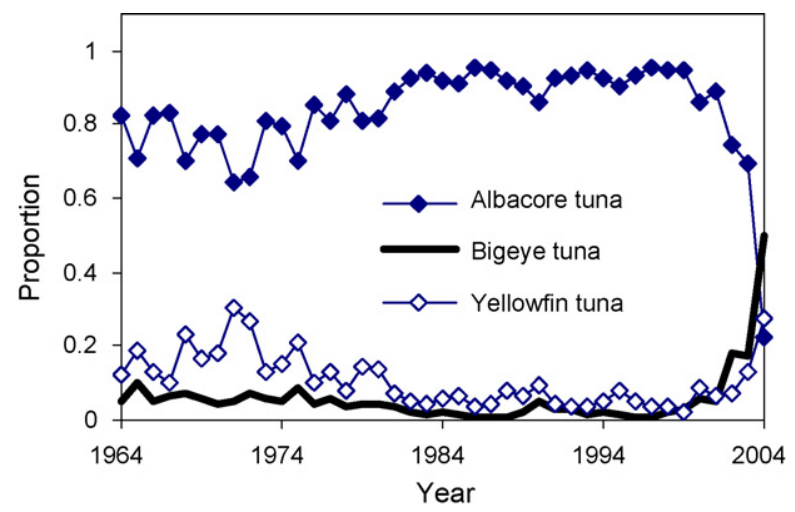

Fig. 3. Proportion of total catch (in numbers; 1964-2004) by the Taiwanese distant-water longline fishery which consisted of albacore, bigeye, and yellowfin.

\subsection{Comparing alternative models and extracting the year effect}

Alternative model structures (i.e. different choices for covariates and two-way interactions among covariates) within each analysis technique (GLM, GAM, and delta) can be compared using standard methods (changes in the residual deviance, likelihood ratio tests, the Akaike Information Criterion (AIC), and the Bayesian Information Criterion (BIC)). However, although based on the same data set, the results of the GLM and GAM analyses cannot be compared directly using likelihood ratio tests because neither is nested within the other. Therefore, the alternative model structures based on different approaches to analyzing the catch and effort data are compared using a variety of criteria, viz.: AIC, BIC, the pseudo-coefficient of determination (pseudo- $R^{2}$ ), and the adjusted pseudo- $R^{2}$ (Swartzman et al., 1992):

Pseudo- $R^{2}=1-\frac{\text { residual deviance }}{\text { null deviance }}$;

Adjusted pseudo- $R^{2}=1-\frac{\text { residual deviance/degree of freedom }}{\text { null deviance/degree of freedom }}$.

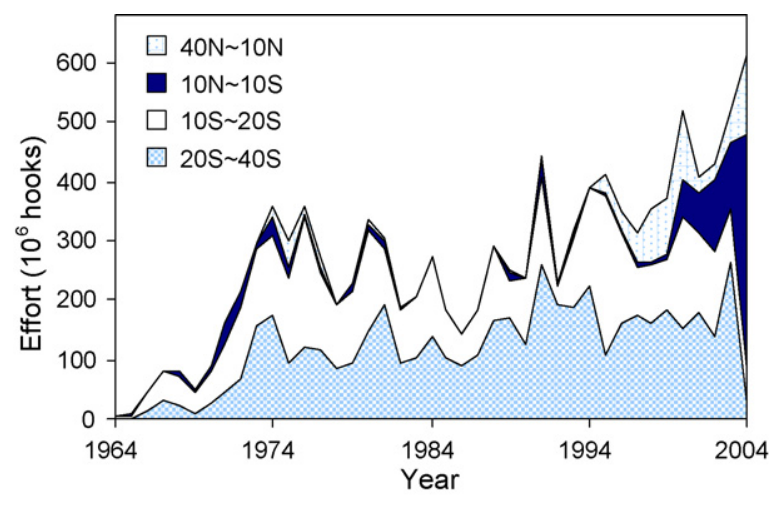

Fig. 5. Annual fishing effort (number of hooks) during 1964-2004 for the Taiwanese distant-water longline fishery.

The standardized catch-rate index was estimated by extracting the year effect in the GLM and GAM models. For the delta approach, the results from the P/A and CPUE models were combined by multiplying the indices of year effects for each model to yield an overall standardized catch index (Wise and Bromhead, 2004).

All of the analyses were conducted by using $\mathrm{R}$ version 2.4.1 (R Development Core Team, 2006).

\section{Results}

The analyses are based on 10,334 records, of which 8843 had a positive catch of bigeye. The fishing effort for the Taiwanese distant-water longline fishery occurred mainly in the area 5 (the south-central Pacific; Fig. 2) because, except during the most recent years, the primary target species of this fishery was albacore (Fig. 3). The highest nominal catch-rates of bigeye occur in area 3 (the central tropical Pacific; Fig. 4), suggesting that spatial covariates are likely to be important in determining catchability for the Taiwanese distant-water longline fishery in the WCPO. Furthermore, there has been a shift in the spatial distribution of this fishery, with substantially more effort occurring in the tropical areas $\left(10^{\circ} \mathrm{N}-10^{\circ} \mathrm{S}\right)$ since 2000 (Fig. 5).

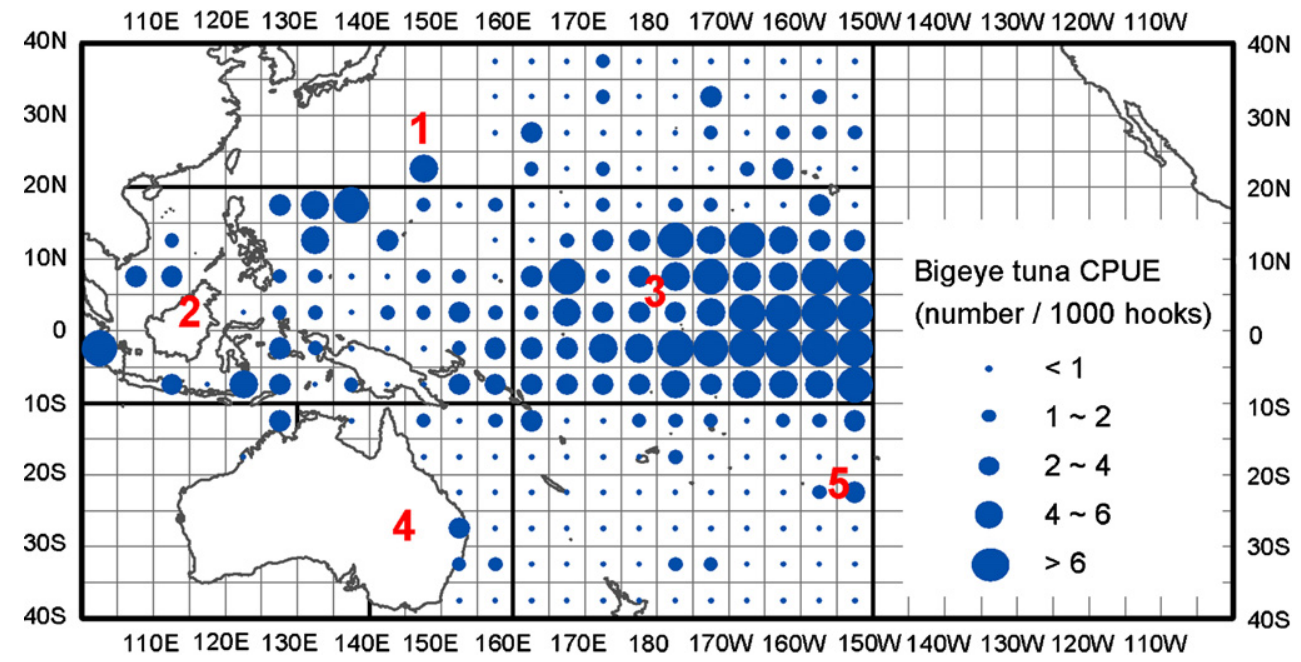

Fig. 4. Distribution of nominal CPUE of bigeye by the Taiwanese distant-water longline fishery (1964-2004, classified into five levels). 
Table 1

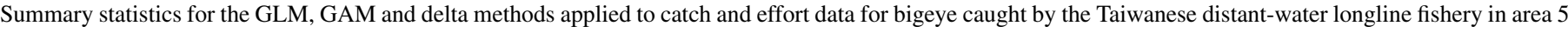

\begin{tabular}{|c|c|c|c|c|c|c|c|c|}
\hline & Null deviance & Null d.f. & Res. deviance & Res. d.f. & Pseudo- $R^{2}$ & Adjusted- $R^{2}$ & AIC & $\mathrm{BIC}$ \\
\hline \multicolumn{9}{|c|}{ GLM + two-way interactions } \\
\hline Model $1^{\mathrm{a}}$ & 7536.5 & 5664 & 5073.6 & 5599 & 0.327 & 0.319 & 15586 & 16031 \\
\hline Model $2^{b}$ & 7536.5 & 5664 & 4626.1 & 5587 & 0.386 & 0.378 & 15087 & 15612 \\
\hline Model $3^{c}$ & 7536.5 & 5664 & 4567.7 & 5575 & 0.394 & 0.384 & 15039 & 15643 \\
\hline \multicolumn{9}{|l|}{ GLM } \\
\hline Model 1 & 7536.5 & 5664 & 5097.6 & 5607 & 0.324 & 0.317 & 15597 & 15989 \\
\hline Model 2 & 7536.5 & 5664 & 4663.3 & 5604 & 0.381 & 0.375 & 15098 & 15510 \\
\hline Model 3 & 7536.5 & 5664 & 4630.2 & 5601 & 0.386 & 0.379 & 15064 & 15496 \\
\hline \multicolumn{9}{|l|}{ GAM } \\
\hline Model 1 & 7536.5 & 5664 & 4884.8 & 5597 & 0.352 & 0.344 & 15375 & 15754 \\
\hline Model 2 & 7536.5 & 5664 & 4394.2 & 5593 & 0.417 & 0.410 & 14784 & 15169 \\
\hline Model 3 & 7536.5 & 5664 & 4256.6 & 5589 & 0.435 & 0.428 & 14611 & 15003 \\
\hline \multicolumn{9}{|l|}{ Delta CPUE } \\
\hline Model 1 & 4061.5 & 4767 & 2338.1 & 4700 & 0.424 & 0.416 & 10271 & 10640 \\
\hline Model 2 & 4061.5 & 4767 & 2187.3 & 4696 & 0.461 & 0.453 & 9961 & 10337 \\
\hline Model 3 & 4061.5 & 4767 & 2065.0 & 4692 & 0.492 & 0.483 & 9695 & 10077 \\
\hline \multicolumn{9}{|l|}{ Delta $P / A$} \\
\hline Model 1 & 4950.2 & 5664 & 3225.5 & 5596 & 0.348 & 0.340 & 3364 & 3742 \\
\hline Model 2 & 4950.2 & 5664 & 3047.2 & 5592 & 0.384 & 0.376 & 3193 & 3578 \\
\hline Model 3 & 4950.2 & 5664 & 3037.9 & 5588 & 0.386 & 0.378 & 3192 & 3584 \\
\hline
\end{tabular}

a Includes an SST:MLD interaction.

b Includes SST:MLD and SST:YFT_CPUE interactions.

c Includes SST:MLD, SST:ALB_CPUE, and YFT_CPUE:ALB_CPUE interactions.

Table 2

Analysis of deviance table for the GLM (excluding the interactions), GAM, and delta approaches

\begin{tabular}{|c|c|c|c|c|c|c|c|c|}
\hline \multirow[t]{2}{*}{ Predictors } & \multicolumn{2}{|l|}{ GLM } & \multicolumn{2}{|l|}{ GAM } & \multicolumn{2}{|c|}{ Delta CPUE } & \multicolumn{2}{|c|}{ Delta $P / A$} \\
\hline & ${ }^{\Delta}$ Dev & $P$ (Chisq) & ${ }^{\Delta}$ Dev & $P($ Chisq $)$ & ${ }^{\Delta}$ Dev & $P$ (Chisq) & ${ }^{\Delta}$ Dev & $P$ (Chisq) \\
\hline$<$ NULL $>$ & 7536.5 & & 7536.5 & & 4061.5 & & 4950.2 & \\
\hline+ Year & 2096.9 & $<.001$ & 2096.9 & $<.001$ & 1434.7 & $<.001$ & 352.9 & $<.001$ \\
\hline +Month & 21.4 & 0.007 & 21.4 & 0.007 & 29.9 & $<.001$ & 27.8 & 0.003 \\
\hline +Latitude & - & - & 396.1 & $<.001$ & 169.1 & $<.001$ & 147.5 & $<.001$ \\
\hline +Longitude & - & - & 79.8 & $<.001$ & 47.8 & $<.001$ & 40.0 & $<.001$ \\
\hline$+\mathrm{SST}$ & 320.3 & $<.001$ & 50.9 & $<.001$ & 36.7 & $<.001$ & 47.4 & $<.001$ \\
\hline$+\mathrm{MLD}$ & 0.2 & 1 & 6.6 & 0.1 & 5.3 & 0.02 & 5.8 & 0.2 \\
\hline +YFT_CPUE & 434.4 & $<.001$ & 490.6 & $<.001$ & 150.9 & $<.001$ & 380.7 & $<.001$ \\
\hline +ALB_CPUE & 33.0 & $<.001$ & 137.6 & $<.001$ & 122.2 & $<.001$ & 125.8 & $<.001$ \\
\hline +Effort & - & - & - & - & - & - & 784.5 & $<.001$ \\
\hline
\end{tabular}

Results are shown in this table for Model 3 and area $5 .{ }^{\Delta}$ Dev denotes the change in deviance.

Table 3

The impact on the explained deviation and BIC of dropping each main effects factor from the GLM (excluding the interaction terms), GAM, and delta models

\begin{tabular}{|c|c|c|c|c|c|c|c|c|}
\hline \multirow[t]{2}{*}{ Predictors } & \multicolumn{2}{|l|}{ GLM } & \multicolumn{2}{|l|}{ GAM } & \multicolumn{2}{|c|}{ Delta CPUE } & \multicolumn{2}{|l|}{ Delta $P / A$} \\
\hline & ${ }^{\Delta}$ Dev & ${ }^{\Delta} \mathrm{BIC}$ & ${ }^{\Delta}$ Dev & ${ }^{\Delta} \mathrm{BIC}$ & ${ }^{\Delta}$ Dev & ${ }^{\Delta} \mathrm{BIC}$ & ${ }^{\Delta}$ Dev & ${ }^{\Delta} \mathrm{BIC}$ \\
\hline$<$ NULL $>$ & 4630.2 & 15496 & 4256.6 & 15003 & 2065.0 & 10077 & 3037.9 & 3584 \\
\hline -Year & $20.6 \%$ & $4.6 \%$ & $16.7 \%$ & $3.5 \%$ & $27.4 \%$ & $8.1 \%$ & $19.1 \%$ & $6.6 \%$ \\
\hline -Month & $0.9 \%$ & $-0.3 \%$ & $0.6 \%$ & $-0.4 \%$ & $0.5 \%$ & $-0.7 \%$ & $0.5 \%$ & $-2.2 \%$ \\
\hline -Latitude & - & - & $0.8 \%$ & $0.2 \%$ & $1.3 \%$ & $0.5 \%$ & $0.5 \%$ & $0.0 \%$ \\
\hline -Longitude & - & - & $1.7 \%$ & $0.5 \%$ & $2.5 \%$ & $1.0 \%$ & $0.8 \%$ & $0.2 \%$ \\
\hline$-\mathrm{SST}$ & $2.8 \%$ & $0.8 \%$ & $0.5 \%$ & $0.1 \%$ & $0.9 \%$ & $0.3 \%$ & $0.3 \%$ & $-0.2 \%$ \\
\hline -MLD & $0.1 \%$ & $-0.1 \%$ & $0.1 \%$ & $-0.1 \%$ & $0.1 \%$ & $-0.1 \%$ & $0.3 \%$ & $-0.1 \%$ \\
\hline -YFT_CPUE & $9.5 \%$ & $3.2 \%$ & $10.6 \%$ & $3.7 \%$ & $6.2 \%$ & $2.7 \%$ & $5.7 \%$ & $4.5 \%$ \\
\hline -ALB_CPUE & $0.7 \%$ & $0.1 \%$ & $3.2 \%$ & $1.1 \%$ & $5.9 \%$ & $2.6 \%$ & $0.3 \%$ & $-0.1 \%$ \\
\hline -Effort & - & - & - & - & - & - & $25.8 \%$ & $21.6 \%$ \\
\hline
\end{tabular}

Results are shown in this table for Model 3 and area $5 .{ }^{\Delta}$ Dev and ${ }^{\Delta}$ BIC denote the change in deviance and in BIC respectively. 

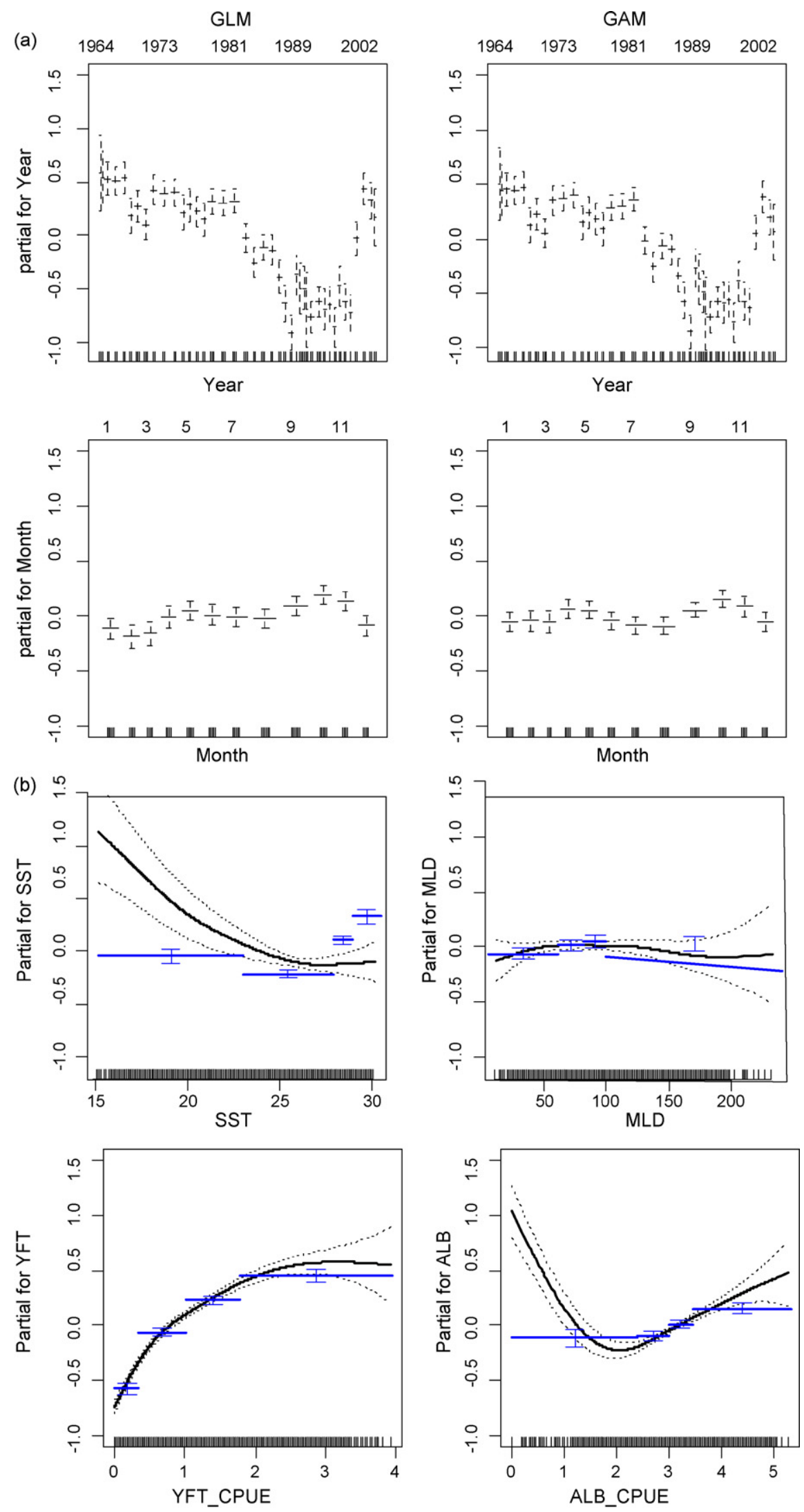

Fig. 6. Impact of the main effects (in log-space) on the catch-rate of bigeye by Taiwanese distant-water longline fishery in area 5. The upper panels show the estimates of the year and month factors from the GLM and GAM for Model 3. The lower panels show the estimated GAM smoothers (curves) and GLM factors (vertical and horizontal bars) for the continuous covariates from this Model. The widths of the horizontal bars indicate the ranges for each continuous variable covered by each categorical factor level. 

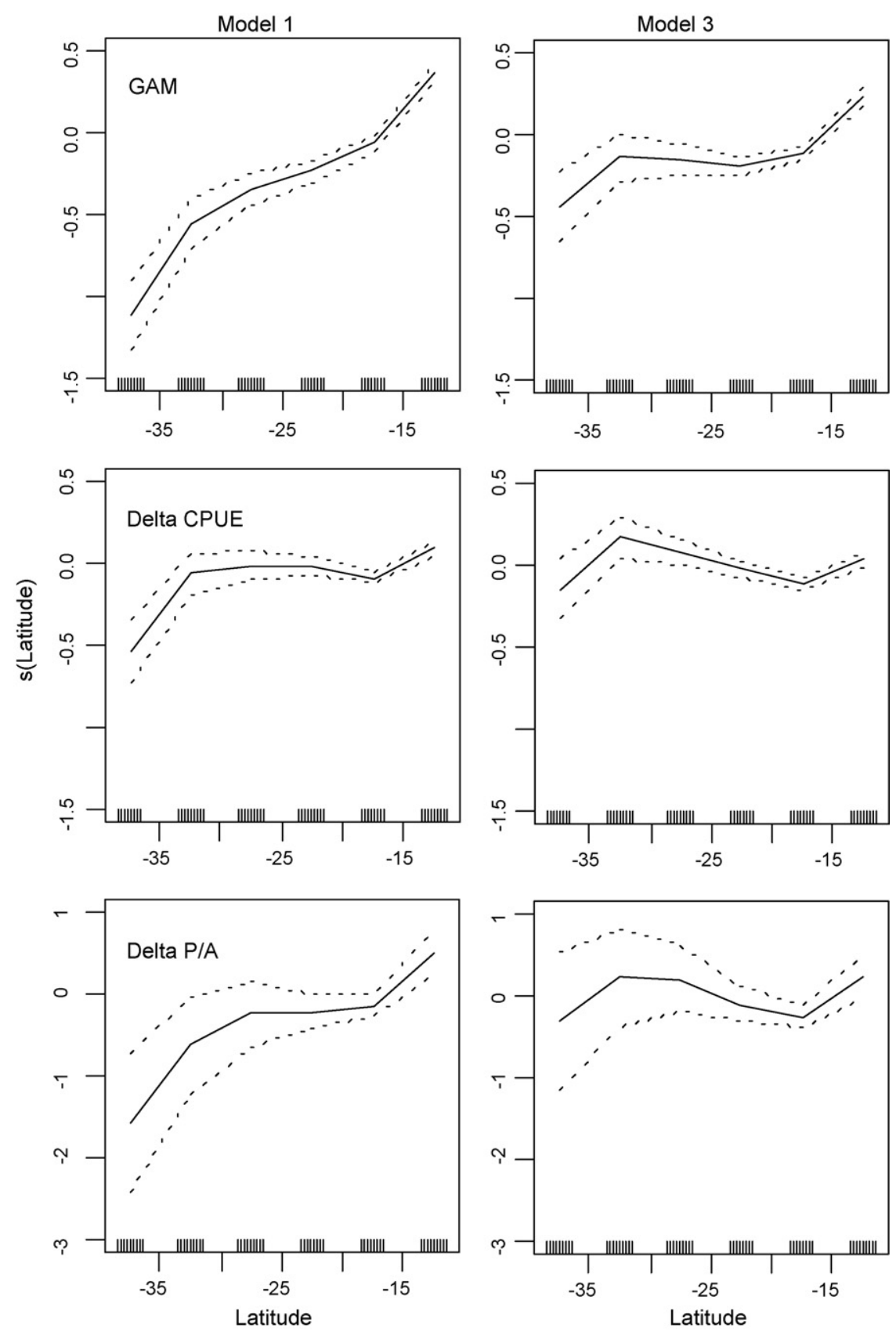

Fig. 7. Partial plots for the latitude effect (in log-space from the mean effect) from Models 1 and 3 based on the GAM and delta models for area 5.

\subsection{Results for area 5}

Tables 1-3 and Figs. 6-8 summarize the results of applying various analysis methods to the data for area 5 (the area with the greatest amount of effort; Fig. 2). The results for the remaining areas are qualitatively identical to those for area 5 .

Table 1 compares the fits of several variants of each of the analysis methods (GLM, GAM, delta) using the deviance, the pseudo- $R^{2}$, the adjusted pseudo- $R^{2}$, and AIC and BIC. Table 1 includes three models based on how the species covariates are included in the analyses: the species covariates are ignored (Model 1), only the catch-rate of yellowfin is used (Model 2), and the catch-rates of both yellowfin and albacore are used (Model
3). Results are shown in Table 1 for GLMs that ignore interactions and those that include the two-way interactions selected using backward selection. Note that the GLMs do not include latitude and longitude as main effects, while only the delta P/A model includes effort as a covariate. Although the GLM and GAM models are not identical structurally (e.g. the GLM models do not include latitude and longitude and the GLM and GAM treat the continuous variables differently), AIC and BIC indicate that the GAM models provide better fits to the data (Table 1). The models with interactions lead, as expected, to higher fractions of the deviance explained, and is selected over the models without interactions by AIC. However, BIC, which imposes a larger penalty on highly parameterized models when there are 

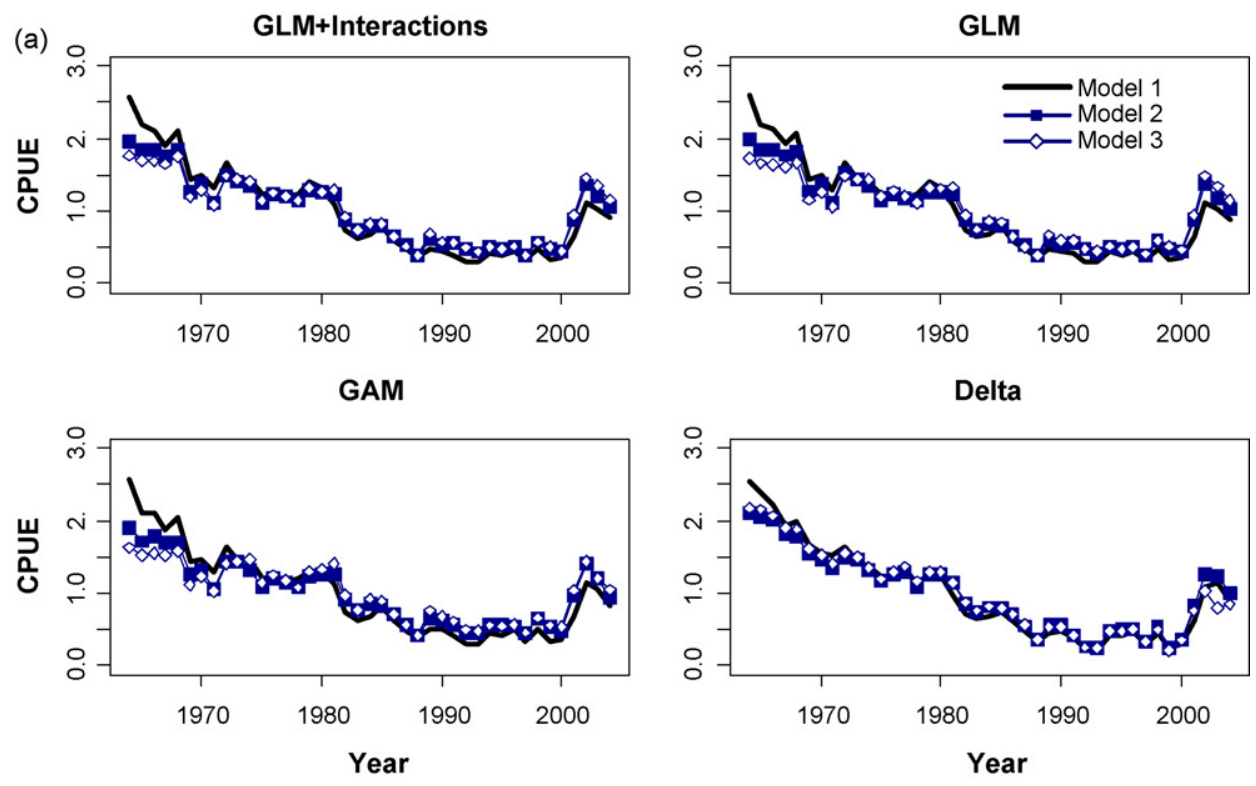

(b)
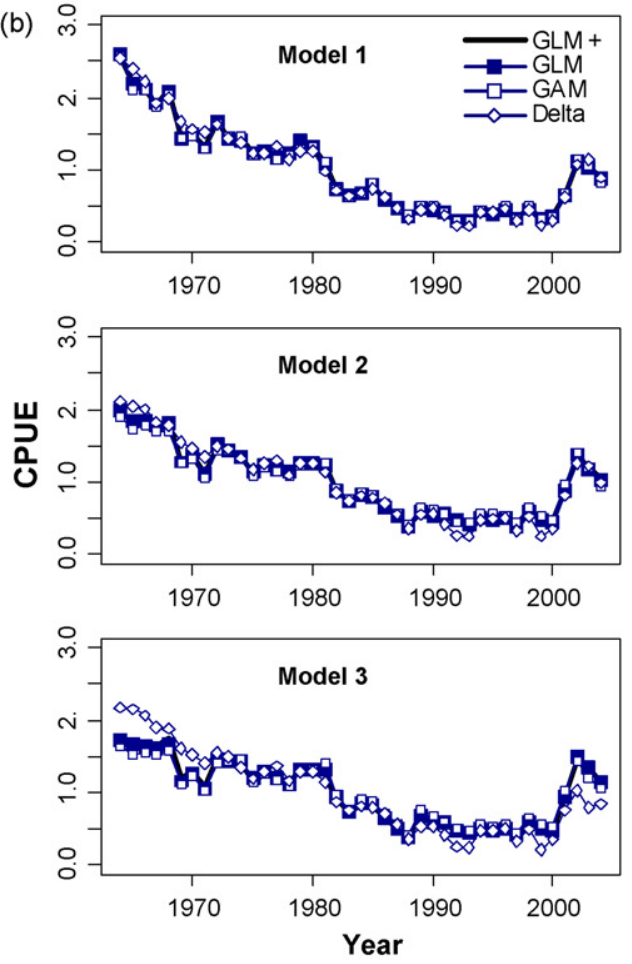

Fig. 8. Relative catch-rates for area 5 based on the GLM, GAM and delta approaches. Results are shown for Models 1-3. GLM+denotes GLM including the interactions selected.

many data points, selects the models without interactions over those with interactions (Table 1). Furthermore, except for the $P / A$ model based on BIC, the two information criteria support inclusion of the species covariates (Model 3).

All of the main effects, except for MLD, were significantly different from zero at $\alpha=0.01$ for Model 3 (Table 2). Leaving year (all analysis methods), effort (delta $P / A$ model), and the catch-rate of yellowfin tuna (GAM and delta models) out of the analyses led to the largest increases in deviance and BIC (Table 3). Leaving month and MLD out of the analysis led to only minor reductions in explained deviance, but to lower (i.e. better) values for BIC. Although largely unnecessary given their low explanatory power, month and MLD are retained in the models explored in the remainder of this paper.

Fig. 6 compares the estimates of the year and month factors from the GLM (no interactions) and the GAM, along with the smoothers for SST, MLD, and the catch-rates of albacore and yellowfin (GAM analysis) and the factor estimates for these covariates (GLM analysis). The results in Fig. 6 are based on Model 3 (the model that includes covariates for the catch-rates of yellowfin and albacore). The year and month factors are very 
similar between the GLM and GAM, with both exhibiting a marked decline during the late 1980s (Fig. 6a). In contrast, there is little change over month in the month factor. The values of the factors from the GLM generally follow the trends in the smoothers for MLD and yellowfin catch-rate and to a lesser extent for albacore and SST (Fig. 6b). The discrepancy between the factor estimates and the smoother predictions for SST is reduced substantially if longitude and latitude are omitted from the analysis. This is not surprising because SST and latitude (in particular) are closely related.

The patterns in the smoothers in the delta CPUE model are very similar to those for the GAM in Fig. 6, while the patterns for delta $P / A$ model have the same qualitative features as for those for the GAM, except (and as expected) that there is strong positive relationship between the probability of capturing at least one bigeye and effort (results not shown).

Other, more striking, features of Fig. 6 are that catch-rates of bigeye are highest in colder $\left(<25^{\circ} \mathrm{C}\right)$ water and when catchrates of yellowfin are high. In contrast, there is little relationship between MLD and catch-rates of bigeye, while the GAM and GLM differ in terms of whether catch-rates of bigeye are increased when the catch-rate of albacore is low. The values for the main effects are not impacted by including the catch-rates for yellowfin and albacore in the analysis, with one notable exception; the latitude smoother is much flatter when account is taken of the species catch-rates (Fig. 7).

The standardized catch-rate indices for area 5 are generally fairly insensitive to the choice of analytical framework (GLM with or without interactions, GAM, and delta) and to whether the catch-rates of yellowfin and albacore are included in the analyses (Fig. 8). The exceptions to this are that Model 1 predicts a slightly more rapid decline in standardized catch-rate before 1970 (Fig. 8a), while the delta model that includes the catch-rates of yellowfin and albacore also predicts a more rapid decline over these years than the GLM and GAM approaches (Fig. 8b).

\subsection{Inter-area comparisons}

The proportion of records with a positive catch of bigeye dropped during the 1990s from values close to one, especially for areas 2 and 4, but increased again towards the end of the period considered in the paper (Fig. 9). The nominal (and standardized) catch-rates differ markedly among areas (Fig. 10). The trends in standardized catch-rate over time for area 3 (where bigeye catch-rates are highest) are similar to those for area 5, although the rate of decline and subsequent recovery in catch-rate for area 3 is greater than for area 5 . There is some evidence for a decline and later recovery in catch-rates for areas 1,2 and 4, but the data are very noisy. The trends in standardized catch-rate for all areas are not particularly sensitive to the choice of analytical framework, whether two-way interactions are included in the GLM analyses, and whether the catch-rates of yellowfin and albacore are included in the analyses. The standardized catch-rates generally track the nominal catch-rates fairly closely. However, and as expected, the standardized catch-rates tend to be less extreme than the nominal catch-rates.

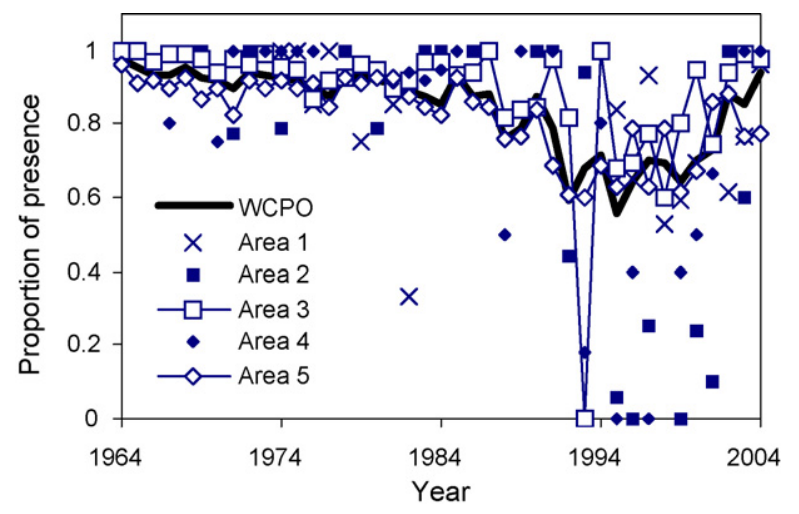

Fig. 9. The proportion of positive catches for the Taiwanese distant-water longline fishery in the WCPO.

\section{Discussion}

Historically, GLM methods have been used to standardize fisheries catch and effort data (e.g., Punt et al., 2000a; Sun and Yeh, 2001; Rodríguez-Marín et al., 2003). However, in more recent years, GAM methods, and methods that analyze the probability of a zero catch and the catch-rate given that the catch is non-zero separately have been used more regularly (Maunder and Punt, 2004; Wise and Bromhead, 2004). In this study, nonlinear relationships between the response variables and latitude, SST and MLD were identified. All three approaches (GLM, GAM and the delta method) can handle non-linear relationships between catch-rates and explanatory variables. This is achieved within the GLM approach by discretizing continuous variables and treating them as fixed effects factors, while the use of smooth additive functions within the GAM approach allows for non-linear relationships. One benefit of the GAM way of handling non-linear relationships is that there are no discontinuities in the impact of covariates, and the selection of the number of parameters is more straightforward. However, the trends in standardized catch-rate are similar between the GAM and GLM (Figs. 8 and 10), indicating a robustness to the choice between the GLM and GAM given the different ways they handle continuous variables that are related in a non-linear way to catch-rates.

The catch-rates of yellowfin and albacore were taken to be covariates and fairly strongly relationships between the catchrates of these species and that of bigeye were identified (Fig. 6). In this study, the impact of latitude appears to be confounded to some extent with that of the catch-rate of yellowfin (Fig. 7), possibly suggesting that operational and targeting practices differ spatially. Care should, however, be taken when including catches and catch-rates of species that are closely related to the species of interest and are by-caught at the same time, as covariates in catch-effort standardizations because this can bias the estimates of the year factors (Maunder and Punt, 2004). Specifically, yellowfin have shown a marked decline in the component of population vulnerable to longline gear (Langley et al., 2005). Given that, the inclusion of this species in the analyses may result in a bias in standardized CPUE for bigeye. The effect of this bias is unlikely to be large in this case, however, because the results 

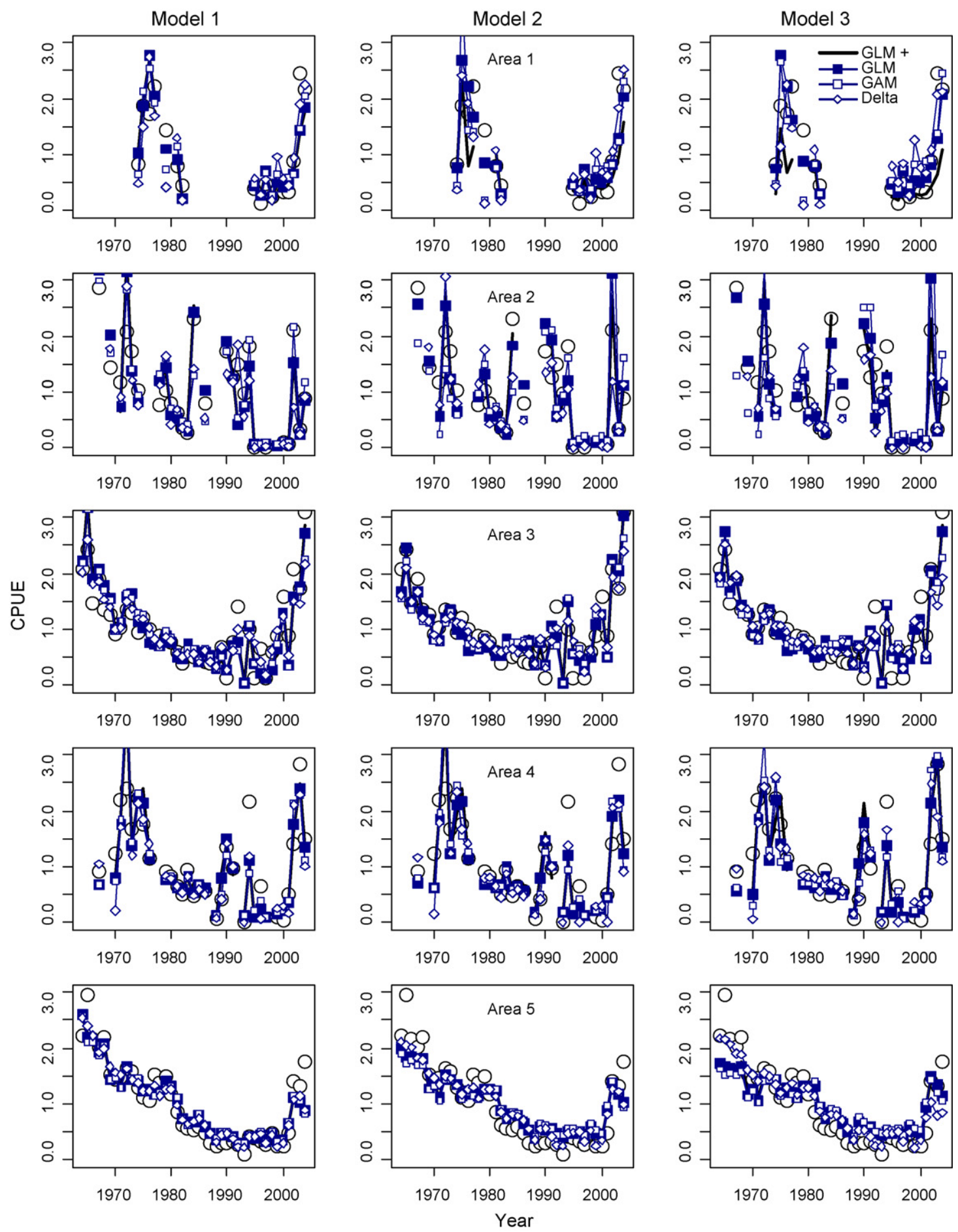

Fig. 10. Nominal (open dots) and standardized (lines) catch-rates by model and area. GLM + denotes GLM including the interactions selected.

are fairly insensitive to whether the catch-rates of yellowfin and albacore are included in the analyses (Fig. 8a).

Including interactions in catch-effort standardizations has become more common recently (e.g. Maunder and Punt, 2004). The most common interactions are among year, month, and area. However, identifying significant interactions between year and other factors means that it is no longer straightforward to use the year factor as a relative index of abundance (Maunder and Punt, 2004). In this study, the data clearly indicate year-area inter- actions (Figs. 9 and 10) which led to separate analyses being conducted for each of five areas in Fig. 2. As such, the analyses of this paper treat all of the factors as interactions with area. Use of the results of this paper as an index of abundance will either require the use of spatially-structured assessment model (Punt et al., 2000a; Hampton et al., 2006), selecting one (or two) of the five areas as being most representative of bigeye abundance, or weighting the catch-rate indices for each area by a measure of habitat (Punt et al., 2000b; Bigelow et al., 2002). Inclusion of 
other two-way interactions did not lead to better fits to the data according to BIC, even for the area with the largest number of data points (Table 1).

The measures of standardized catch-rate (Fig. 10) could be used as indices of relative abundance in stock assessments, as the effects of temporal, spatial and environmental effects on catchability have been removed. However, even after standardization, care needs to be taken when including catch-rate indices in stock assessments because the analyses ignore some potentially important factors. For example, the standardization analyses of this paper ignore changes in how the gear is used and deployed. Specifically, although data exist on the number of hooks between floats, these data could not be included in the analyses because this information is not available for the entire period 1964-2004. Changes in gear usage are, however, likely to be correlated with targeting practices so the inclusion of the catch-rates of yellowfin and albacore in the models might be able to capture some of the changes in gear usage, at least implicitly. For example, the Taiwanese distant-water longline fishery has shifted to tropical areas in recent years, which has led to a reduction in the proportion of albacore in the catches (Fig. 3). Although SST and MLD were included in the analyses, other environmental and oceanographic variables exist that, if available, could help evaluate changes in catchability further. These variables are, however, likely to be correlated with SST, so including SST in the analyses may be sufficient (Watters and Maunder, 2001; Lu et al., 2001; Lee et al., 2005).

In summary, a variety of methods (GLM, GAM, and delta) were applied to standardize the catch-rates of bigeye in the Taiwanese distant-water longline fishery. All of these methods provided fairly similar results (Figs. 8 and 10), suggesting that although the methods differ conceptually, they are all sufficiently flexible to capture the key features of the data. Moreover, although the information criteria support inclusion of the catchrates of other species and there is a fairly strong relationship between the catch-rate of bigeye and that of yellowfin (Fig. 6), the qualitative impression of how standardized catch-rate has changed over time is robust to whether these covariates are included in the analyses. In contrast, the results of these analyses highlight the importance of spatial factors (Figs. 9 and 10), as the data support different trends in standardized catch-rates (and perhaps abundance) in different areas. In principle, some of the indices in Fig. 10 (e.g. for area 3) could be included along with indices of standardized CPUE for Japanese longliners in stock assessments, although care needs to be taken because of the potential for catch-rate indices not to track abundance.

\section{Acknowledgements}

We sincerely express our appreciation to two anonymous reviewers whose comments improved the manuscript. This study was in part supported financially by the Fisheries Agency, Council of Agriculture, Taiwan, through the grants 94-AS-14.1.2-FA-F1(6), 95-AS-14.1.2-FA-F1(8) and 96-AS15.1.2-FA-F2(4) to Chi-Lu Sun.

\section{References}

Andrade, H.A., Tozetto, A.L., Santos, J.A.T., 2005. The effect of environmental factors and of the fishermen strategy on the skipjack tuna (Katsuwonus pelamis) CPUE in the southwest Atlantic. ICCAT Coll. Vol. Sci. Pap. 58, 350-358.

Bigelow, K.A., Hampton, J., Miyabe, N., 2002. Application of a habitat-based model to estimate effective longline fishing effort and relative abundance of Pacific bigeye tuna (Thunnus obesus). Fish. Oceanogr. 11, 143155 .

Guisan, A., Edwards Jr., T.C., Hastie, T., 2002. Generalized linear and generalized additive models in studies of species distributions: setting the scene. Ecol. modell. 157, 89-100.

Hampton, J., Kleiber, P., Takeuchi, Y., Kurota, H, Maunder, M. 2003. Stock assessment of bigeye tuna in the western and central Pacific Ocean, with comparisons to the entire Pacific Ocean. SCTB16 working paper, BET-1.

Hampton, J., Langley, A., Kleiber, P., 2006. Stock assessment of bigeye tuna in the western and central Pacific Ocean, including an analysis of management options. In: SA WP-2. 2nd meeting of the scientific committee of the Western and Central Pacific Fisheries Commission WCPFC-SC2, Manila, Philippines, 7-18 August 2006.

Hastie, T.J., Tibshirani, R.J., 1990. Generalized Additive Models. Chapman and Hall, New York.

Langley, A., Bigelow, K., Miyabe, N., Maunder, M., 2005. Longline CPUE indices for yellowfin and bigeye in the Pacific Ocean using GLM and statistical habitat standardisation methods. In: SA-WP-8, 1st Meeting of the Scientific Committee of the Western and Central Pacific Fisheries Commission WCPFC-SC1, Noumea, New Caledonia, 8-19 August 2005.

Lee, P.F., Chen, I.C., Tzeng, W.N., 2005. Spatial and temporal distribution patterns of bigeye tuna (Thunnus obesus) in the Indian Ocean. Zoolog. Stud. 44 (2), 260-270.

Lo, N.C., Jacobson, L.D., Squire, J.L., 1992. Indices of relative abundance from fish spotter data based on delta-lognormal models. Can. J. Fish. Aquat. Sci. $49,2515-2526$

Lu, H.J., Lee, K.T., Lin, H.L., Liao, C.H., 2001. Spatio-temporal distribution of yellowfin tuna Thunnus albacares and bigeye tuna Thunnus obesus in the tropical Pacific Ocean in relation to large-scale temperature fluctuation during ENSO episodes. Fish. Sci. 67, 1046-1052.

Matsumoto, T., 1998. Preliminary analyses of age and growth of bigeye tuna (Thunnus obesus) in the western Pacific Ocean based on otolith increments. In: Deriso, R.S., Bayliff, W.H., Webb, N.J. (Eds.), Proceedings of the First World Meeting on Bigeye Tuna. Inter-Am. Trop. Tuna Comm., Spec. Rep. 9, 238-242.

Maunder, M.N., Punt, A.E., 2004. Standardizing catch and effort data: a review of recent approaches. Fish. Res. 70, 141-159.

Nelder, J.A., Wedderburn, R.W.M., 1972. Generalised linear models. J. R. Statist. Soc. A $137,370-384$

Okamoto, H., Chang, S.K., Yeh, Y.M., Hsu, C.C., 2004. Standardized Taiwanese longline CPUE for bigeye tuna in the Indian Ocean up to 2002 applying targeting index in the model. IOTC-2004-WPTT-10.

Ortiz, M., 2005. Standardized catch rates for bigeye tuna (Thunnus obesus) from the pelagic longline fishery in the northwest Atlantic and the Gulf of Mexico. ICCAT Col. Voll. Sci. Pap. 58, 137-152.

Ortiz, M., Arocha, F., 2004. Alternative error distribution models for standardization of catch rates of non-target species from a pelagic longline fishery: billfish species in the Venezuelan tuna longline fishery. Fish. Res. 70, 275-297.

Punt, A.E., Walker, T.I., Taylor, B.L., Pribac, F., 2000a. Standardization of catch and effort data in a spatially-structured shark fishery. Fish. Res. 45, 129145 .

Punt, A.E., Pribac, F., Walker, T.I., Taylor, B.L., Prince, J.D., 2000b. Stock assessment of school shark Galeorhinus galeus based on a spatially-explicit population dynamics model. Mar. Freshw. Res. 51, 205-220.

R Development Core Team, 2006. R: A language and environment for statistical computing. R Foundation for Statistical Computing, Vienna, Austria. ISBN 3-900051-07-0, URL http://www.R-project.org.

Rodríguez-Marín, E., Arrizabalaga, H., Ortiz, M., Rodríguez-Cabello, C., Moreno, G., Kell, L.T., 2003. Standardization of bluefin tuna, Thunnus thyn- 
nus, catch per unit effort in the baitboat fishery of the Bay of Biscay (Eastern Atlantic). ICES J. Mar. Sci. 60, 1216-1231.

Sacau, M., Pierce, G.J., Wang, J., Arkhipkin, A.I., Portela, J., Brickle, P., Santos, M.B., Zuur, A.F., Cardoso, X., 2005. The spatio-temporal pattern of Argentine shortfin squid Illex argentinus abundance in the southwest Atlantic. Aquat. Living Resour. 18, 361-372.

Stefánsson, G., 1996. Analysis of groundfish survey abundance data: combining the GLM and delta approaches. ICES J. Mar. Sci. 53, 577-588.

Stephens, A., MacCall, A., 2004. A multispecies approach to subsetting logbooks data for purposes of estimating CPUE. Fish. Res. 70, 299-310.

Sun, C.L., Yeh, S.Z., 2001. Updated CPUE of central and western Pacific bigeye tuna from Taiwanese tuna fisheries. BET-5, SCTB 14, Noumea, New Caledonia, 9-16 August 2001.
Sun, C.L., Huang, C.L., Yeh, S.Z., 2001. Age and growth of the bigeye tuna, Thunnus obesus, in the western Pacific Ocean. Fish. Bull. 99, 502509.

Swartzman, G., Huang, C., Kaluzny, S., 1992. Spatial analysis of Bering Sea groundfish survey data using generalized additive models. Can. J. Fish. Aquat. Sci. 49, 1366-1378.

Watters, G.M., Maunder, M.N., 2001. Status of bigeye tuna in the eastern Pacific Ocean In Stock Assessment Report 1: status of the tuna and billfish stocks in 1999. IATTC, 109-201.

Wise, B., Bromhead, D., 2004. Striped marlin abundance: standardisation of CPUE. In: Bromhead, D., Pepperell, J., Wise, B., Findlay, J. (Eds.), Striped Marlin: Biology and Fishery. Bureau of Rural Sciences, Canberra, pp. 171-194. 